\title{
LETTERS
}

\section{The authors respond to comments from Vermaak and Stahlbrand}

We thank Drs. Vermaak ${ }^{1}$ and Stahlbrand ${ }^{2}$ for their interest in our case. ${ }^{3}$ The patient did not have jaundice. Physical examination showed no yellowing of her sclera, and her total bilirubin was $1.02 \mathrm{mg} / \mathrm{dL}$. We performed an abdominal computed tomography scan for several reasons. First, the patient had severe right upper quadrant pain that was worsening. Second, although the sensitivity and specificity of abdominal ultrasonography for detecting gallstones are excellent if the ultrasound is performed by an experienced examiner, ability to detect gallstones varies depending on the skill of the examiner. Third, although the possibility of gallstones was low owing to the patient's age and the absence of jaundice, it was necessary to evaluate the common bile duct, because we could not rule out the possibility that gallstones may have passed into the common bile duct before the imaging was performed. It took 5 days to receive the results of the antibody test for Epstein-Barr virus. No antibiotics were used during that time. The patient's leukocytes were elevated $\left(17 \times 10^{9} / \mathrm{L}\right)$, with $48 \%$ lymphocytes. Ebell and colleagues ${ }^{4}$ reported that in infectious mononucleosis, the positive likelihood ratio for leukocytes $>10 \times 10^{9} / \mathrm{L}$ was 2.7, and the negative likelihood ratio was 0.79 . In this study, lymphocytes $>45 \%$ had a positive likelihood ratio of 9.3 , and a negative likelihood ratio of 0.38 , and lymphocytes $>4 \times 10^{9} / \mathrm{L}$ in patients older than 18 years had a positive likelihood ratio of 26 and a negative likelihood ratio of $0.04 .{ }^{4}$ We suspected infectious mononucleosis based on the patient's symptoms and signs, including the lymphocytosis. In this case, atypical lymphocytes were not found on the first blood test, but they were found in a blood test on the second day of the patient's hospital stay. It is common for atypical lymphocytes to be absent initially.

\section{Hiroaki Nakagawa MD}

Department of General Internal Medicine, Fukushima Medical University,

Fukushima, Japan

\section{Yasushi Miyata MD PhD}

Department of Primary Care and

Community Health, Aichi Medical

University, Nagakute, Japan

Cite as: CMAJ 2021 July 26;193:E1144. doi: 10.1503/cmaj.79189

\section{References}

1. Vermaak JS. Epstein-Barr virus acute acalculous cholecystitis [letter]. CMAJ 2021;193:E1143.

2. Stahlbrand E. Computed tomography scan for mononucleosis [letter]. CMAJ 2021;193:E1142.

3. Nakagawa H, Miyata Y. Epstein-Barr virus infection associated with acute acalculous cholecystitis in a 20-year-old woman. CMAJ 2021;193:E696.

4. Ebell MH, Call M, Shinholser J, et al. Does this patient have infectious mononucleosis?: The rational clinical examination systematic review. JAMA 2016;315:1502-9.

Competing interests: None declared.

Content licence: This is an Open Access article distributed in accordance with the terms of the Creative Commons Attribution (CC BY-NC-ND 4.0) licence, which permits use, distribution and reproduction in any medium, provided that the original publication is properly cited, the use is noncommercial (i.e., research or educational use), and no modifications or adaptations are made. See: https://creativecommons.org/ licenses/by-nc-nd/4.0/ 